\section{Metabolism of Pyruvic Oxime}

Pyruvic oxime, as shown by Lees and Quastel ${ }^{1}$, undergoes rapid nitrification in soil during continuous perfusion. It was thought by these authors that this molecule might be intermediate in the process of ammonia conversion into nitrate during soil nitrification: This, however, is not the case, since further studies-both perfusion and manometric-have shown :

(a) that ethyl urethane and methionine, which inhibit nitrification of ammonia in soil, have no inhibitory effects on the nitrification of pyruvic oxime; potassium chlorate also has no action.

(b) that soils enriched with ammonia- or nitriteoxidizing organisms cannot oxidize pyruvic oxime immediately though they oxidize ammonium ions or nitrite respectively.

(c) that soils enriched with organisms oxidizing pyruvic oxime by continuous perfusion with it cannot oxidize ammonium ions. Typical figures supporting these statements are given in Table 5.

\section{Table 5}

(A) Pyruvic oxime enriched sofl. Oxygen uptakes in $3 \mathrm{hr}$. in c.mm. $\begin{array}{lr}\text { Water at } 37^{\circ} \mathrm{C} . & 155 \\ \text { Pyruvic oxime }(0.01 \mathrm{M}) & 380 \\ \text { Ammonium chloride }\left(0^{\circ} \cdot 01 \mathrm{M}\right) & 155\end{array}$

(B) Perfusion of ammonium chloride enriched soil. Percentage (B) Perfusion of ammonium chloride enriched soil. Percentage
nitrogen appearing as nitrite in $24 \mathrm{hr}$. $0 \cdot 001 M$ potassium chlorate Ammonium chloride $(0.01 M)$ Pyruvic oxime $(0.01 \mathrm{M})$

31

(C) Perfusion of fresh soil. Percentage nitrogen appearing as nitrite in four days. $0.001 M$ potassium chlorate present in each. Methionine $(0.01 M)$
Methionine $(0.01 M)$ and
pyruvic oxime $(0.01 M)$
Pyruvic oxime $(0.01 M)$

These results point to the conclusion that soils contain organisms, presumably heterotrophic, that can bring about a speedy oxidation of pyruvic oxime to nitrite. Oxalacetic oxime will also undergo nitrification, but no other oxime yet studied has been found to have this property. Oximes of acetone, formaldehyde, acetoacetic ester and benzoin have been tested and found to be inert. Moreover, they do not inhibit the nitrification of pyruvic oxime. The only substances yet found to inhibit the nitrification of pyruvic oxime in soil are sodium azide and sodium cyanide, both vigorous respiratory poisons.

Work, in collaboration with Dr. J. W. Stevenson, of the Bacteriology Department, McGill University, is in progress and has now resulted in the isolation of the organisms responsible from the enriched soils.

Whether or not pyruvic oxime is an intermediate in nitrogen metabolism of soil bacteria is a matter for further investigation. It is clear, however, that the presence in soil of a group of organisms that can rapidly nitrify pyruvic oxime without the intervention of the autotroph Nitrosomonas points to the possibility that the process of nitrification in soil may not be wholly accomplished by the autotrophic organisms and that the intervention of heterotrophs bringing about a direct nitrification of organic nitrogen compounds may take place.

\footnotetext{
'Lees, H., and Quastel, J. H., Chem. and Indust., 26, 238 (1944); Biochem. J., 40, 803 (1946).

${ }^{2}$ Audus, L. J., Nature, 158, 419 (1946).

'Meyerhof, O., Pflüg. Arch. ges. Physiol., 164, 253 (1916); 165, 229 (1916); 166, 240 (1917).

4 Lees, H., and Quastel, J. H., Nature, 155, 276 (1945).
} INTERNATIONAL COUNCIL FOR THE EXPLORATION OF THE SEA

$\mathrm{O}^{\mathrm{N}}$ the invitation of the British Government, the International Council for the Exploration of the Sea (Conseil Permanent.International pour l'Exploration de la Merfarsinged to hold its thirty-seventh annual megting $\boldsymbol{A}$ Edinburgh during October 3-11. The ocgasipn was the more welcome since it was the first on which the Gpuncil had met in Scotland, while it is twenty year $\$$ ince it last met in Great Britain (Lqddon) in (Cotobbr 1929. Arrangements for the meeting were hade by the Scottish Home Department.

The Council met under the presidency of Dr. K. A. Andersson of Sweden, who was re-elected president for the year 1949-50. Government delegates and experts from Iceland, Norway, Sweden, Denmark, Finland, Holland, Belgium, France, Spain, Portugal, Eire and the United Kingdom were present, and were very glad to welcome observers from the United Nations Food and Agriculture Organisation, from the United States and from Australia, together with visitors from various marine laboratories. It was regretted that representetives from Poland were unable to be present. H.M.S. Cygnet and H.M.S. Welcome (Fishery Protection Flotilla) visited the port of Leith for this occasion, as well as research vessels from Sweden, Belgium, France, England and Scotland, all of which were on view during the meeting.

The members of the Council and visitors were welcomed by the Lord Provost of Edinburgh, Sir Andrew Murray, and the joint Parliamentary UnderSecretary of State for Scotland, Mr. J. J. Robertson, when the Council held its first meeting in the City Chambers on October 3. Reference was made at this meeting to the loss sustained by the Council in the death during 1949 of Prof. Martin Knudsen of Copenhagen. Subsequent meetings of the Council were held in the Department of Zoology on the invitation of the University of Edinburgh.

Special arrangements were made to precede the meetings of the Council by a conference of herring experts from the various interested countries. This was held in St. Andrew's House, Edinburgh, during September 29-October 1 and was followed by a special 'herring meeting' of the Council on October 4, when the chief item was an address by Prof. A. C. Hardy (Oxford), who reviewed the whole field of herring research and made stimulating proposals for its development.

During the conference of herring experts, the various countries reported on their work since the previous meeting held in Aberdeen in 1946, and great interest was shown in the preliminary recaptures which have been obtained by Sweden, Denmark and Scotland following new methods of herring tagging. Previous attempts to label herring with external tags have been unsuccessful, so that future recaptiures of such herring promise to provide greatly needed information about their migrations, growth, etc. A recommendation was passed that every effort should be made by all countries concerned with herring fisheries to undertake further tagging experiments, and in particular to compare the efficiency of the different types of tags in order to select those most likely to give a high percentage of recaptures.

Much interest was shown also in the preliminary results of applying the American and Canadian 
methods of internal tagging to the herring fisheries of Norway and Iceland (where the greater use of fish. processing plants makes such methods possible), particularly in view of the growing evidence of large-scale seasonal migrations between north Iceland and Norway. Special arrangements were recommended for securing further information on the occurrence of these herring shoals with the help of all vessels of the member countries which operate in these northern waters.

Among other aspects of herring research, developments in the use of echometers were discussed, while several papers were read on the influence of the fishing on the herring stocks. Here the absence of really adequate statistics was felt, and particularly in view of the meeting of the Food and Agriculture Organisation at The Hague in August 1949, it was recommended that all countries take steps to provide standardized statistics of unit catches, so that an adequate watch can be kept on the signs of stock changes in the various fisheries and their possible causes. It was felt by all the representatives that so valuable have been the two herring meetings, and so great is the need for the closest intermational collaboration, that the various herring experts should now have regular opportunities to meet. All the area committees concerned with herring problems endorsed this feeling, and the Council agreed to establish a herring committee forthwith.

The scientific proceedings closed with another special meeting to review research problems in the fields of the commercial fisheries for Crustacea and Mollusca. A large number of interesting papers were circulated and discussed, and it was decided to adjourn the meeting until the next session of the Council at Copenhagen in 1950 , so that progress and problems could be further discussed.

Apart from ad hoc meetings such as these, the greater part of the work of the Council is done by the standing committees dealing with research in the various regions and in certain special fields of study. During these meetings the progress of European fisheries research during $1948-49$ was reviowed, programmes for 1950 were discussed and arrangements made for their co-ordination where necessary. In particular, the preliminary results of the international hydrographical-biological surveys of 1948 and 1949 were discussed, and arrangements made for a combined long-term fisheries research programme for the North Sea and the waters to the north-west and north-east. The arrangements for publishing the long-established Bulletins Hydrographiques and the much more recent Annales Biologiques were also reviewed, as were the arrangements for collecting, standardizing and publishing statistics of the various fisheries (Bulletins Statistiques) in which the advice and experience of the Fisheries Division of the Food and Agriculture Organisation were welcomed. The special international programme of salmon tagging was extended for another three years, and a co-ordinated investigation of salmon migrations around the Irish coast was recommended.

Great interest was shown during the meeting of the Southern North Sea Committee in Dr. A. V. Tåning's account of the large-scale experimental transplantation by the Danish Government of plaice to the Dogger Bank area. So far, one million plaice have been transplanted, and the results of this major experiment will be awaited eagerly by all marine workers who are aware of the earlier experiments in this field.
The following committee chairmen were elected for the year 1949-50: Consultative, Dr. R. S. Clark; North-Eastern Area, Mr. G. Rollefsen; North-Western Area, Dr. A. Vedel Tåning ; Atlantic, Prof. Jean Le Gall; Northern North Sea, Dr. C. E. Lucas ; Southern North Sea, Mr. R. S. Wimpenny ; Transition Area, Dr. E. M. Poulsen; Baltic Area, Dr. Chr. Hessle; Hydrographical, Mr. Helge Thomsen; Plankton, Mr. F. S. Russell; Statistical, Dr. Nils Rosen; Salmon and Trout, Prof. K. Dahl; Whaling, Dr. N. A. Mackintosh; Herring, Dr. W. C. Hodgson; Finance, Dr. K. A. Andersson.

During the course of the discussion, various social gatherings were arranged, together with excursions, including a visit to the laboratory of the Scottish Marine Biological Association at Millport. Following the meeting, a number of the Continental delegates and experts took the opportunity to attend the joint meeting of the Challenger Society for the Promotion of the Study of Oceanography, on the invitation of the Society and the Marine Laboratory of the Scottish Home Department, Aberdeen.

\section{AQUATIC LOCOMOTION}

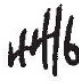

$T$ THE possibility that some aquatic animals may possess a propulsive mechanism of greater efficiency than that of a torpedo or submarine was the subject of a stimulating discussion at a joint meeting of Soctiony D (Zoology) and G (Engineering) at the Nepto meeting of the British Association.

Brof, L E. Burrily first described the distribution of fol tit andotensure around a smooth streamlined bday such as afish or a submarine, deeply immersed in a fluid and advancing with uniform velocity. In such circumstances there is a positive or increased pressure on the forward part of the body which tends to retard the motion, and a similar increased pressure on the aftermost parts tending to assist the motion. On the middle part of the length there is a region of decreased pressure; but, owing to the shape, the fore and aft components here are small. In an ideal fluid, the net fore and aft component of the pressures and sub-pressures would be zero; but in an actual fluid such as water, when viscosity is present, there may be a small positive resistance retarding themotion, known as the pressure resistance. This is, however, usually very small when compared with the resistance caused by the rubbing of the fluid against the surface of the body, which is known as the skinfrictional resistance.

Prof. Burrill then proceeded to discuss the mechanism of this frictional resistance. He described the existence of a layer of fluid close to the surface of the body within which the forward velocity of the entrained fluid diminishes, rapidly at first and then more slowly, until a zone is reached where the forward velocity is very small. The thickness of this layer increases from forward to aft along the form. For low speeds of advance and short lengths of body, the flow within this boundary layer may be completely laminar, and successive layers of fluid appear to slide over each other smoothly and steadily. This type of flow may persist up to Reynolds numbers ( $V L / v$, where $V$ is velocity, $L$ is length of body and $\nu$ is kinematic viscosity (viscosity/density)) of about $5 \times 10^{6}$. For greater speeds and longer lengths of surface, the flow within the boundary layer is usually laminar for only a short length at the forward end. 